\title{
UV, FTIR and DFT Studies of Chlorochromones in Polar Protic and Polar Aprotic Solvent Mixtures
}

\author{
Walmik B. Shirsath \\ Associate Professor, Department of Chemistry, Karm.A.M. Patil Arts, Comm. and
}

Kai Annasaheb N.K. Patil Science Senior College, Pimpalner. Tal. Sakri, Dist. Dhule. 424306, Maharashtra, India.

\begin{abstract}
UV and FTIR spectroscopic studies containing 0.01 and $0.001 \mathrm{~m}$ solute Chlorochromones with electron donating and withdrawing groups) were done in $10-90 \%(\mathrm{w} / \mathrm{w})$ methanol (ME) in DMSO/DMF solvent mixtures at room temperature The $\lambda \max$ of solutes vary with the $\%$ of ME. The decrease in $\lambda_{\max }$ of all solutes was more in ME + DMSO than in ME + DMF. The amount of blue shift (lower wave length) has been used as a measure to the strength of hydrogen bond. Absence of $\mathrm{n} \rightarrow \pi^{*}$ excitation in solute $+\mathrm{ME}+\mathrm{DMSO} / \mathrm{DMF}$ was ascribed due to hydrogen bond formation. An irregular trends in $v \mathrm{OH}, v \mathrm{C}=\mathrm{O}, v \mathrm{~S}=\mathrm{O}, v \mathrm{C}-\mathrm{Cl}, v \mathrm{C}-\mathrm{H}, v \mathrm{NH}$ etc. with increase of $\mathrm{ME}$ in solution at a particular concentration of solute indicated structure of the medium changed with ME content. In certain compositions of 0.01 and $0.01 \mathrm{~m}$, no changes in vibration frequencies were detected. Hydrogen bond formation of ME with carbonyl of, $\mathrm{CL}_{1}$ and $\mathrm{CL}_{2}$ was well supported by shifting of normal $v \mathrm{C}=\mathrm{O}$ to $1650-1640 \mathrm{~cm}^{-1}$.In the case of $0.01 \mathrm{~m} \mathrm{CL}_{1}$, there was an initial increase in $\mathrm{vOH} \approx 50 \% \mathrm{ME}$. Further addition of $\mathrm{ME}$ in the system dropped it. Dilute solute concentration (i.e. $0.001 \mathrm{~m}$ ) did not show much appreciable change for this frequency upto $40 \% \mathrm{ME}$, while further addition of $\mathrm{ME}$ decreased the same. The magnitude of $v \mathrm{~S}=\mathrm{O}$ remain unchanged after $10 \% \mathrm{ME}$ for both 0.001 and $0.01 \mathrm{~m}$ solute concentrations. The $v \mathrm{C}-\mathrm{Cl}$ was around $700 \mathrm{~cm}-1$ in $20-80 \% \mathrm{ME}$. These results demonstrate the presence of strong interactions among the molecules of the solvent as well as between solute and solvent. Geometry optimizations of heterocyclic compounds, pure solvents and their 1:1 and 1:1:1 complex were carried out using the DFT/B3LYP method with medium size 6-31G (d) basis set available in G03(W) series of programs All optimized geometries were viewed through Gauss View 4.1 software to know exact nature of intermolecular interaction.
\end{abstract}

Keywords: Chalcones, Chlorochromones UV, FTIR, DFT and molecular interaction.

\section{INTRODUCTION}

Chlorochromones has played a crucial part in the development of theory in heterocyclic chemistry. Heterocyclic compounds of chlorochromones have played an important role in medicinal chemistry serving as key templates central to the development of numerous therapeutic agents. Natural chalcones and synthetic chalcones show various biological effects as antiinflamatory, antitumour, antibacterial, anti-tubercular, antiviral anti protozol antidepressant insecticidal, antidiabetic.[1-5] Chlorochromones are used extensively as synthons in organic synthesis reports [6] The synthesis [7] of $\alpha, \beta$-unsaturated carbonyl compounds is one of main structural component in various naturally occurring and biologically essential substance. Several strategies for the synthesis of these system based on formation of carboncarbon bond have been reported and among them the direct Aldol-condensation and Claisen-Schimdt condensation still occupy prominent position. It is well known that most natural or synthetic chalcones are highly active with extensive pharmaceutical and medicinal application. Chalcones are found to be effective as antiviral cardiovascular and antiinflammatory agents. Reaction of 2'-hydroxy-5' acetamido chalcones with catalytic amount of iodine in DMSO affords flavones molar amount of mercuric (II) acetate in pyridine gives aurones while with phenyl hydrazine and hydrazine hydrate gives Chlorochromones in triethanolamine medium [8].

Chlorochromones constitute a medicinal important class of heterocyclic small molecules that have shown potential bioactivity in numerous screening tests. Chlorochromones systems are known to be biologically active and are important constituents of many pharmaceutical and agrochemical products on the synthesis and pharmacology of chlorochromones revealed that some of these compounds exhibited a wide local anesthetic activity. Therefore, the synthesis of these compounds was of interest largely on account of their biological activity chlorochromones are possessing diverse biological activities such as anticarcinogenic, antidiabetic, anticonvulsant, anti-inflammatory, antifungal, antiviral, and analgesic and antioxidant activities and represent a very important class of biologically active agents and the focus of a significant amount of research interest. In particular, chlorochromones derivatives have found use as antitumor, antibacterial, antifungal, antiviral, antiparasitic, antitubercular and insecticidal agents 


\section{International Advanced Research Journal in Science, Engineering and Technology}

Vol. 8, Issue 6, June 2021

DOI: $10.17148 /$ IARJSET.2021.8617

chlorochromones are known for their pronounced antimicrobial activity. The new chlorochromones containing methylthio phenyl group in position 3 and aryl groups in position 5 and evaluated there in vivo analgesic and antiinflammatory properties. [9-12]

Ultra violet spectroscopy is also known as electronic spectroscopy. It involves the promotion of electron ( $\sigma, \pi$ and $n$ electrons) from the ground state to higher energy state. It is very useful to measure the number of conjugated double bonds and also aromatic conjugation within the various molecules.[13] The solvent effect on spectra resulting from electronic transition is primarily dependent on the chromophore and the nature of transition ( $\Pi-\Pi^{*}$ and $n-\Pi^{*}$ transition. $\sigma \rightarrow \sigma^{*}, n \rightarrow \sigma^{*}, \Pi \rightarrow \Pi^{*}, n \rightarrow \Pi^{*}$ and charge- transfer absorption) IR spectroscopy is a common technique that is used to identify the major functional group in a compound. The identification of these groups depends upon the amount of IR radiation absorbed and the particular frequency at which these groups absorb. It is the leading method for identification of hydrogen bonds. For instance, the formation of an O-H--O hydrogen bond elongates and weakens the O-H bond. The resulting red shift of the $\mathrm{O}-\mathrm{H}$ bond stretching frequency can be easily detected and its magnitude indicates the strength of the hydrogen bond. IR spectrum measure the degree of the molecular vibration and rotation of the bonds in the molecule. Each type of the functionality will absorb at certain characteristics frequency and with characteristic strength. IR spectrum is an important record which gives sufficient information about the structure of a compound. [14] IR spectroscopy is used to establish whether a given sample of an organic substance is identical with another or not. This is because large numbers of absorption bands are observed in the IR spectra of organic molecules and the probability that any two compounds will produce identical spectra is almost zero. So, if two compounds have identical IR spectra, then both of them must be samples of the same substances.

\section{EXPERIMENTAL SECTION}

Aqueous $\mathrm{KOH}(0.02 \mathrm{~mol})$ was added to the suspension of 2-hydroxyacetophenone $(0.01 \mathrm{~mol})$ and pchlorobenzaldehyde $(0.01 \mathrm{~mol})$ in ethanol. The reaction mixture was stirred at room temperature for overnight. The reaction mixture was then poured onto ice cold water and acidified with $\mathrm{HCl}(1 \mathrm{M})$. The solid obtained was filtered and crystallized from ethanol to get pure chalcone 1. It's structural formula shown in fig. 1.<smiles>O=C(/C=C/c1ccc(Cl)cc1)c1ccccc1O</smiles>

Fig.1. Chalcone 1:(2E)-3-(4-chlorophenyl)-1-(2-hydroxyphenyl)prop-2-en-1-one

Same procedure was followed to synthesize Chalcone 2 from m-nitrobanzaldehyde. Chalcone 1 (0.001mol) was dissolved in minimum quantity of DMSO $(5-6 \mathrm{ml})$ then $2 \mathrm{~g}$ of anhydrous $\mathrm{CuCl}_{2}$ was added and reaction mixture was reflux for 3 hrs. This reaction mixture was kept overnight. Further, the reaction mass was quenched into crushed ice and left for $1 \mathrm{hr}$. A white solid was obtained which was filtered \& washed with three times by water and 1:1 $\mathrm{HCl}$ till the colour of the mother liquor was colorless. The solid product $\left(\mathrm{CL}_{1}\right)$ was purified by recrystallisation from ethanol. Fig.2 indicates Chlorochromone $\left(\mathrm{CL}_{1}\right)$ as shown below<smiles>O=c1c(Cl)c(-c2ccc(Cl)cc2)oc2ccccc12</smiles>

Fig.2. Chlorochromone (CL1) 3-chloro-2-(4-chlorophenyl)-4H-chromen-4-one

Same procedure was followed to synthesize Chalcone 2 from m-nitrobanzaldehyde. Similarly $\mathrm{CL}_{2}$ as shown in fig.3 was prepared by using Chalcone 2 . 
<smiles>O=c1c(Cl)c(-c2cccc([N+](=O)[O-])c2)oc2ccccc12</smiles>

$\mathrm{CL}_{2}$

Fig.3. Chlorochromone (CL2) 3-chloro-2-(3-nitrophenyl)-4H-chromen-4-one

All chemicals were of standard grade (SRL) with purity near to $99 \%$ Binary mixtures were prepared by mixing a known mass of each liquid. Important synthesized hetrocyclic compounds of Chlorochromones were used. The solids were characterized by chemical as well as by spectroscopic methods. Binary liquid mixtures of DMSO and DMF with $\mathrm{ME}(\mathrm{x} 1)$ of compositions $0-100$ mass $\%$ as well as $\mathrm{x}_{1}=0.1$ to 0.9 were prepared by mixing a known mass of each liquid in an airtight Stoppard bottle. Solutions containing 0.001 to $0.01 \mathrm{~m}$ hetrocyclies $\left(\mathrm{CL}_{1}\right.$ and $\left.\mathrm{CL}_{2}\right)$ in binary mixtures (as a solvent) were also prepared by usual method.

\subsection{UV measurements:}

UV Spectra of above solvent systems and solutions were recorded on a UV 2400 PC in the wavelength range 200-400 $\mathrm{nm}$. The scan speed was fast and sampling interval was about 2.0. The UV measurements are reported directly in $\mathrm{nm}$, and the corresponding range in $\mathrm{cm}$.

\subsection{IR measurements:}

FTIR spectra of experimental solvent systems and solutions were recorded on a FTIR spectrometer (Model: SIMADZU $8400 \mathrm{~S}$ PC) by using $\mathrm{KBr}$ pellet in the region $400-4000 \mathrm{~cm}^{-1}$ with $4.0 \mathrm{~cm}^{-1}$ resolution. Selected stretching frequencies of solvents and solutes used in this work are listed in Table 1 and 2.

Table 1. Selected neat IR frequencies of solvents

\begin{tabular}{|c|c|c|c|c|c|}
\hline \multicolumn{2}{|c|}{ ME } & \multicolumn{2}{c|}{ DMSO } & \multicolumn{2}{c|}{ DMF } \\
\hline Group & $v$ & Group & $v$ & Group & $v$ \\
\hline O-H & 3570,3450 & S=O & 1051.19 & C=O & 1752 \\
\hline C-H & 2833.00 & C-H & 2995,2963 & C-H & 2944.35 \\
\hline C-H & 2945.40 & -- & -- & -- & -- \\
\hline C-O & 1030.02 & -- & -- & -- & -- \\
\hline
\end{tabular}

Table 2. IR stretching frequencies of CL1and $\mathrm{CL}_{2}$

\begin{tabular}{|c|c|c|c|}
\hline \multicolumn{2}{|c|}{$\mathrm{CL}_{1}$} & \multicolumn{2}{c|}{$\mathrm{CL}_{2}$} \\
\hline Group & $v$ & Group & $v$ \\
\hline $\mathrm{C}-\mathrm{H}$ & 3067 & $\mathrm{C}-\mathrm{H}$ & 3077,2965 \\
\hline $\mathrm{C}=\mathrm{O}$ & 1657 & $\mathrm{C}=\mathrm{O}$ & 1668 \\
\hline $\mathrm{C}=\mathrm{C}$ & 1607 & $\mathrm{C}=\mathrm{C}$ & 1607,1589 \\
\hline $\mathrm{Cl}$ & 758 & $\mathrm{~N}=\mathrm{O}$ & 1350,1533 \\
\hline- & -- & $\mathrm{C}-\mathrm{Cl}$ & 762 \\
\hline
\end{tabular}

\subsection{Optimization of geometries using Gaussian Package:}

Geometry optimizations of heterocyclic compounds, pure solvents and their 1:1 and 1:1:1 complexes were carried out using the DFT/B3LYP method with medium size 6-31G (d) basis set available in G03(W) series of programs [15].

All optimized geometries were viewed through Gauss View 4.1 software. Figs. 4-6 include optimized geometries of solvents and solutes under investigation. 


\section{IARJSET}

International Advanced Research Journal in Science, Engineering and Technology

Vol. 8, Issue 6, June 2021

DOI: $10.17148 /$ IARJSET.2021.8617

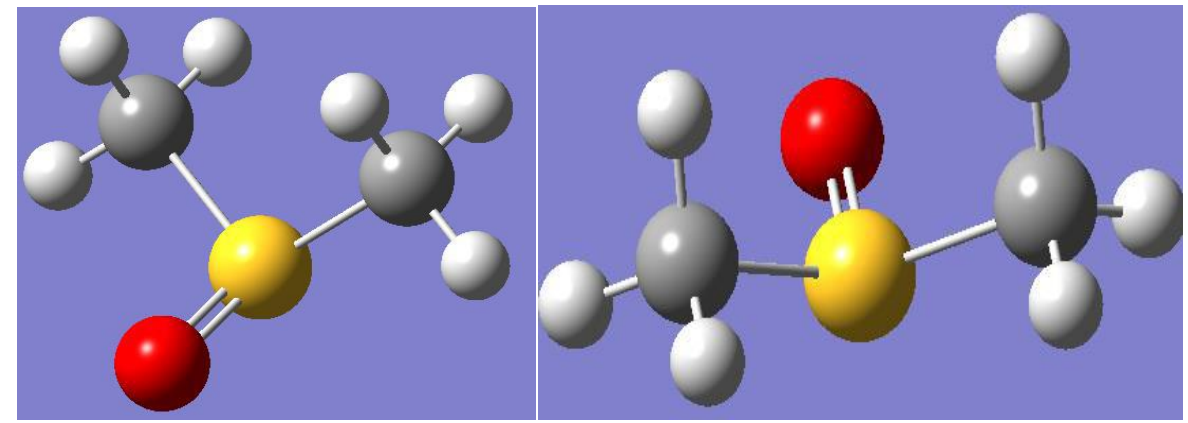

(a)

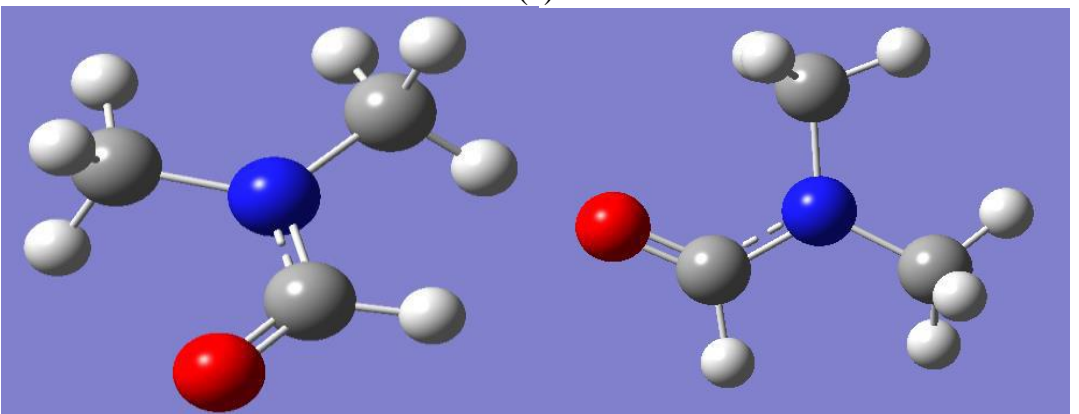

(b)

Fig.4. (a) Optimized geometries of DMSO using B3LYP/6-31G (d) basis set (b) optimized geometries of DMF using B3LYP/6-31G (d) basis set

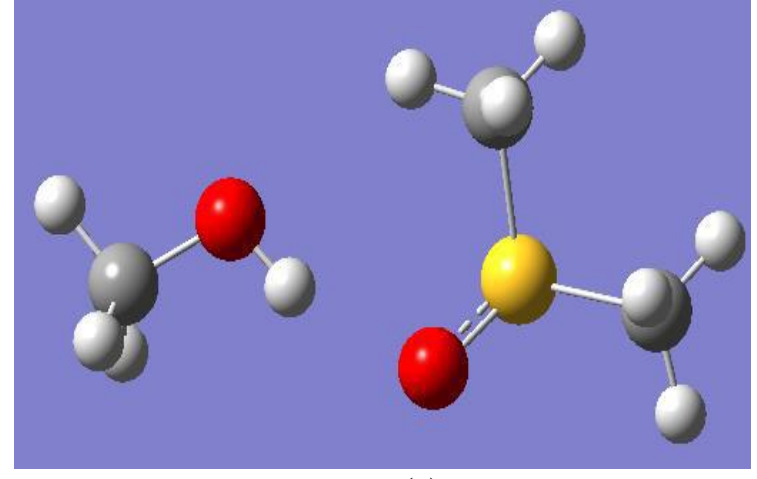

(a)

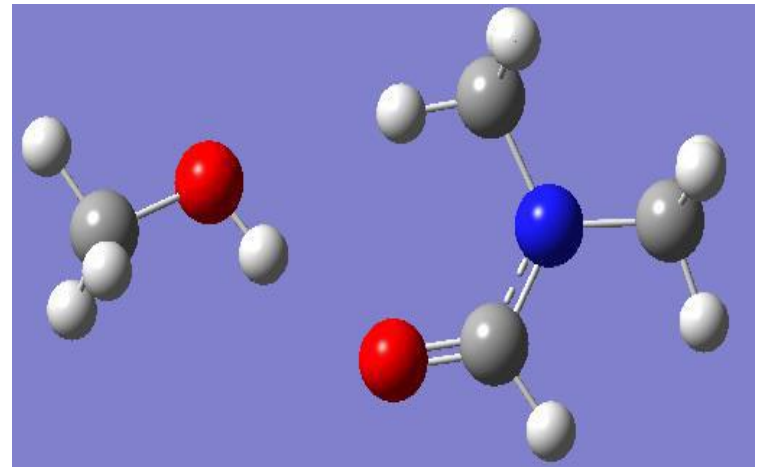

(b)

Fig.5. (a) Optimized geometry of Hydrogen bond interactions: ME with DMSO (b) Optimized geometry of Hydrogen bond interactions: ME with DMF

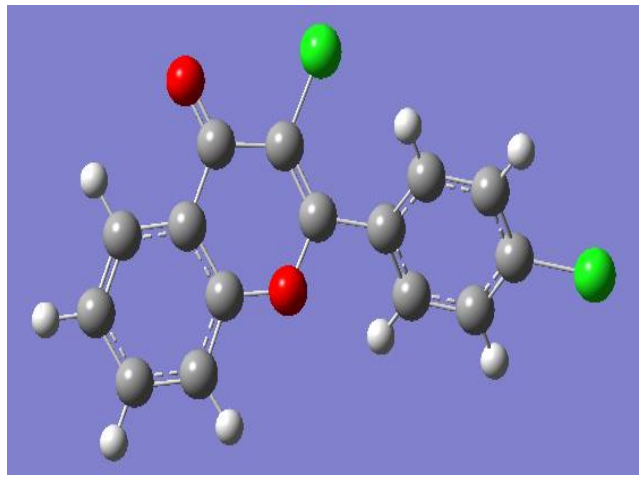

(a)

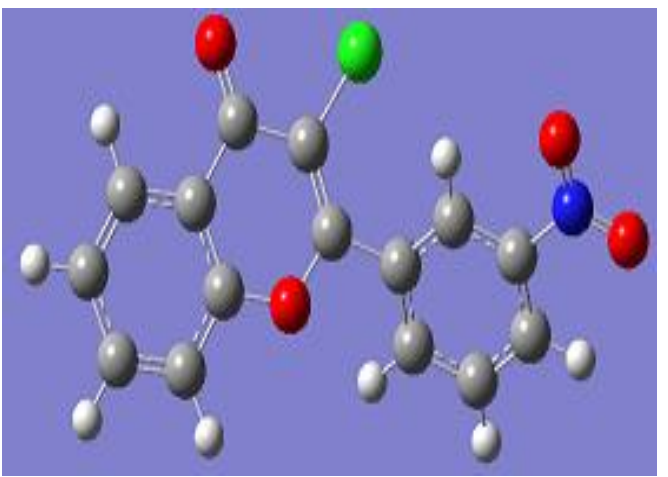

(b)

Fig.6. (a) DFT optimized geometries of $\mathrm{CL}_{1}$ by using B3LYP/ 6-31G (d) basis set (b) DFT optimized geometries of $\mathrm{CL}_{2}$ by using B3LYP/ 6-31G(d) basis set 
International Advanced Research Journal in Science, Engineering and Technology

Vol. 8, Issue 6, June 2021

DOI: $10.17148 /$ IARJSET.2021.8617

\section{RESULTS AND DISCUSSION}

\section{1: IR and theoretical studies:}

Experimental results of FTIR stretching frequencies of some functional groups of mixtures of ME with DMSO and DMF are listed in Table 3. For ME + DMSO, maximum $v O H$ (at low $\mathrm{x}_{1}$ ) decreased upon dilution $\left(\mathrm{x}_{1} \approx 0.2-0.9\right)$. The magnitude of all these frequencies is higher than that for pure ME. This may be due to the breaking of ME aggregates making more free monomers of it in the system. The $v \mathrm{~S}=\mathrm{O}$ of DMSO disappeared at $1051.19 \mathrm{~cm}^{-1}$ in all compositions and appeared at a lower but almost constant value suggesting hetero association between ME and DMSO. In case of ME $+\mathrm{DMF}$, both $\mathrm{vOH}$ and $v \mathrm{C}=\mathrm{O}$ decreased with the increase in the amount of $\mathrm{x} 1$ in the binary system suggesting breaking of aggregates of ME as well as DMF. An aldehyde $v \mathrm{C}-\mathrm{H}$ at $2944 \mathrm{~cm}^{-1}$ moved down upon addition of co- solvent indicating decreased double bond character of $\mathrm{C}=\mathrm{O}$ in presence of $\mathrm{ME}$. The hydrogen bond formation between hydroxyl proton of $\mathrm{ME}$ and oxygen of $\mathrm{O}=\mathrm{S}(\mathrm{DMSO}) / \mathrm{O}=\mathrm{C}(\mathrm{DMF})$ is further confirmed by the theoretical investigation. Fig. 5 depicts minimum energy structures for 1:1 complex of components of binaries using our legal licensed copy G03 (W) software. From above studies, hetero intermolecular interactions are in the following order: ME + DMSO $>$ ME + DMF

Table 3. Selected IR frequencies for binaries ME $\left(\mathbf{x}_{1}\right)+\operatorname{DMSO}\left(1-\mathrm{x}_{1}\right)$

\begin{tabular}{|c|c|c|}
\hline $\mathbf{x}_{\mathbf{1}}$ & $\mathbf{O H}$ & $\mathbf{S}=\mathbf{O}$ \\
\hline 0 & -- & 1051.19 \\
\hline 0.1 & 3387.11 & 1031.95 \\
\hline 0.2 & 3381.33 & 1031.95 \\
\hline 0.3 & 3379.4 & 1031.95 \\
\hline 0.4 & 3379.4 & 1030.02 \\
\hline 0.5 & 3377.47 & 1030.02 \\
\hline 0.6 & 3373.61 & 1030.02 \\
\hline 0.7 & 3358.18 & 1030.02 \\
\hline 0.8 & 3346.61 & 1030.02 \\
\hline 0.9 & 3346.61 & 1030.02 \\
\hline 1 & 3352.39 & -- \\
\hline
\end{tabular}

\begin{tabular}{|c|c|c|c|}
\multicolumn{5}{|c|}{ ME $\left(\mathbf{x}_{\mathbf{1}}\right)+$ DMF (1- $\left.\mathbf{x}_{\mathbf{1}}\right)$} \\
\hline $\mathbf{X}_{\mathbf{1}}$ & $\mathbf{O H}$ & $\mathbf{C = O}$ & $\mathbf{C - H}$ (Aldehyde) \\
\hline 0 & -- & 1675.00 & 2944.35 \\
\hline 0.1 & 3458.48 & 1674.27 & 2931.90 \\
\hline 0.2 & 3439.19 & 1674.27 & 2933.83 \\
\hline 0.3 & 3433.41 & 1672.69 & 2935.76 \\
\hline 0.4 & 3419.9 & 1672.34 & 2935.76 \\
\hline 0.5 & 3421.83 & 1664.62 & 2935.76 \\
\hline 0.6 & 3387.11 & 1668.48 & 2939.61 \\
\hline 0.7 & 3365.9 & 1668.48 & 2941.54 \\
\hline 0.8 & 3352.39 & 1670.41 & 2943.47 \\
\hline 0.9 & 3352.39 & 1648.48 & 2943.47 \\
\hline 1 & 3352.39 & -- & - \\
\hline
\end{tabular}

Selected IR frequencies for 0.01 and $0.001 \mathrm{~m} \mathrm{CL}_{1}$ in ME + DMSO are tabulated in Table 4. In the case of $0.01 \mathrm{~m} \mathrm{CL}_{1}$, there was an initial increase in $\mathrm{vOH}$ upto $50 \% \mathrm{ME}$. Further addition of $\mathrm{ME}$ in the system dropped it. Dilute solute concentration (i.e. $0.001 \mathrm{~m}$ ) did not show much appreciable change for this frequency upto $40 \% \mathrm{ME}$, while further addition of ME decreased the frequency. Carbonyl frequency of $0.01 \mathrm{~m} \mathrm{CL}$ in both pure solvents was higher than in the 


\section{International Advanced Research Journal in Science, Engineering and Technology}

Vol. 8, Issue 6, June 2021

DOI: $10.17148 /$ IARJSET.2021.8617

binaries due to hydrogen bond formation with ME. The magnitude of $v \mathrm{~S}=\mathrm{O}$ remain unchanged after $10 \% \mathrm{ME}$ for both solute concentrations. The $\mathrm{vC}-\mathrm{Cl}$ was around $700 \mathrm{~cm}^{-1}$ in $20-80 \% \mathrm{ME}$. These two results demonstrate the presence of strong interactions among the organic molecules of the solvent as well as between solute and solvent. In $0.001 \mathrm{~m} \mathrm{CL}_{1}$, detection of $v \mathrm{C}=\mathrm{O}$ was difficult in all compositions of $\mathrm{ME}$ except in $10 \% \mathrm{ME}$.

The probable reason is the mixing of these frequencies with aromatic $v C=C$ frequencies $\left(1500-1650 \mathrm{~cm}^{-1}\right)$. Furthermore, $v \mathrm{C}=\mathrm{O}$ for all systems of $\mathrm{CL}_{1}+\mathrm{ME}+\mathrm{DMSO}$ are higher than that of $\mathrm{F}_{1}+\mathrm{ME}+\mathrm{DMSO}$. The probable explanation is the presence of chlorine atom next to carbonyl group in $\mathrm{CL}_{1}$ which exerts a field effect (i.e. $\alpha$-halo effect on carbonyl frequency). Table 5 includes $v \mathrm{OH}, v \mathrm{C}-\mathrm{H}, v \mathrm{C}=\mathrm{O}, v \mathrm{C}-\mathrm{N}$ and $v \mathrm{C}-\mathrm{Cl}$ of CL1 in $\mathrm{ME}+\mathrm{DMF}$. In a particular concentration of solute, $v \mathrm{OH}$ decreased with $\mathrm{ME}$ content. All these frequencies are higher in dilute solutions $(0.001 \mathrm{~m})$ upto 50\% ME and then decreased till pure ME content. Aldehyde $v \mathrm{C}-\mathrm{H}$ and $\mathrm{vC}-\mathrm{N}$ slightly increased with addition of polar solvent whereas $\mathrm{vC}=\mathrm{O}$ and $\mathrm{vC}-\mathrm{Cl}$ values were almost identical in solvent mixtures. This reveals that in $\mathrm{DMF}$ systems, the intermolecular interactions between unlike molecules are relatively low as compared to that in DMSO systems due to the low dielectric constant of it (DMF). This is also confirmed from the magnitudes of $v \mathrm{OH}$ and $v \mathrm{C}=\mathrm{O}$ which are higher in DMSO than in DMF. From the perusal of the Table 6 it is seen that no $\lambda_{\max }$ was recorded in the usual $\mathrm{UV}$ region for yellowish coloured $\mathrm{CL}_{1}$ in DMSO. As the $\% \mathrm{ME}$ was increased $(30 \% \mathrm{ME})$, the decrease in $\lambda_{\max }$ corresponding to $\pi \rightarrow \pi^{*}$ was observed. The absorbance of $\mathrm{CL}_{1}$ was maximums in these regions. From $40 \% \mathrm{ME}$ onwards, red shifts $(\approx 300 \mathrm{~nm})$ were observed.

Table 4. IR vibration frequencies of 0.01 and $0.001 \mathrm{~m} \mathrm{CL} 1+\mathrm{ME}+\mathrm{DMSO}$ system

\begin{tabular}{|c|c|c|c|c|c|c|c|c|}
\hline \multirow[t]{2}{*}{$\% \mathrm{ME}$} & \multicolumn{2}{|l|}{ vOH } & \multicolumn{2}{|c|}{$\begin{array}{l}v \mathrm{C}=\mathrm{O} \\
\quad \text { of } \mathrm{CL}_{1}\end{array}$} & \multicolumn{2}{|c|}{$v S=0 / v C-O$} & \multicolumn{2}{|l|}{$v \mathrm{C}-\mathrm{Cl}$} \\
\hline & $0.01 \mathrm{~m}$ & $0.001 \mathrm{~m}$ & $0.01 \mathrm{~m}$ & $0.001 m$ & $0.01 \mathrm{~m}$ & $0.001 \mathrm{~m}$ & $0.01 m$ & $0.001 m$ \\
\hline 0 & -- & -- & 1662.69 & 1664.62 & 1055.1 & $\begin{array}{c}1062.81, \\
1049.31\end{array}$ & 698.25 & 698.25 \\
\hline 10 & 3383.26 & 3410.26 & 1658.84 & 1662.69 & 1057.03 & $\begin{array}{l}1053.17 \\
1035.81\end{array}$ & 698.25 & 700.18 \\
\hline 20 & 3389.04 & 3392.9 & 1662.69 & -- & 1028.09 & 1031.95 & 702.11 & 700.18 \\
\hline 30 & 3389.04 & 3387.11 & 1658.84 & -- & 1030.02 & 1031.95 & 702.11 & 702.11 \\
\hline 40 & 3385.18 & 3383.26 & -- & -- & 1030.02 & 1031.95 & 702.11 & 702.11 \\
\hline 50 & 3387.11 & $\begin{array}{l}3377.47, \\
3398.69\end{array}$ & 1656.91 & -- & 1028.09 & 1031.95 & 702.11 & 702.11 \\
\hline 60 & $\begin{array}{c}3379.40, \\
3362.04\end{array}$ & $\begin{array}{l}3371.68 \\
3344.68\end{array}$ & 1656.91 & -- & 1030.02 & 1030.02 & 704.04 & 704.04 \\
\hline 70 & 3358.18 & 3379.4 & 1656.91 & -- & 1030.02 & 1028.09 & 705.97 & 704.04 \\
\hline 80 & 3354.32 & 3350.46 & 1656.91 & -- & 1030.02 & 1030.02 & 705.97 & 700.18 \\
\hline 90 & 3350.46 & $\begin{array}{l}3348.54, \\
3338.89\end{array}$ & -- & -- & 1030.02 & 1030.02 & 650.03 & 667.39 \\
\hline 100 & 3350.46 & 3344.68 & 1766.78 & -- & 1030.02 & 1030.02 & 653.89 & 655.82 \\
\hline
\end{tabular}

These observations are attributed to two effects. Polar protic solvent $\mathrm{ME}$ forms hydrogen bond with $\mathrm{C}=\mathrm{O}$ of solute, therefore binds the lone pair of electrons leading to blue shift. Chlorine is not forming hydrogen bond with ME, therefore its lone pair of electrons interact with the $\pi$ electron cloud of aromatic ring of $\mathrm{CL}_{1}$ resulting in a red shift. Absence of $n$ $\rightarrow \pi^{*}$ excitation in the lower \%ME in $\mathrm{CL}_{1}+\mathrm{ME}+\mathrm{DMF}$ is ascribed due to hydrogen bond formation between solute oxygen i.e. $\mathrm{C}=\mathrm{O}$ with hydrogen of $\mathrm{ME}$. The $\lambda_{\max }$ around $300 \mathrm{~nm}$ in remaining ME rich regions corresponds to $\mathrm{n} \rightarrow \pi^{*}$ transition (chlorine lone pair and aromatic system). The effect of $\alpha$-chlorine has been observed in both solvent systems of $\mathrm{CL}_{1}$. Thus compared with $\mathrm{F}_{1}$ systems, $\mathrm{CL}_{1}$ systems have higher $\lambda_{\max }$ in all solvent mixtures. 


\section{IARJSET}

International Advanced Research Journal in Science, Engineering and Technology

Vol. 8, Issue 6, June 2021

DOI: $10.17148 /$ IARJSET.2021.8617

Table 5. Selected IR data of 0.01 and $0.001 \mathrm{~m} \mathrm{CL}$ in $\mathrm{ME}+\mathrm{DMF}$

\begin{tabular}{|c|c|c|c|c|c|c|c|c|c|c|}
\hline \multirow[t]{2}{*}{$\begin{array}{c}\% \\
\mathrm{ME}\end{array}$} & \multicolumn{2}{|c|}{ vOH } & \multicolumn{2}{|c|}{$\begin{array}{c}\text { vC-H } \\
\text { (aldehyde) }\end{array}$} & \multicolumn{2}{|c|}{$\begin{array}{c}v \mathbf{C}=\mathbf{O} \\
\left(\mathrm{CL}_{1} \text { or Aldehyde }\right)\end{array}$} & \multicolumn{2}{|c|}{$v \mathrm{C}-\mathrm{N}$} & \multicolumn{2}{|c|}{$v \mathrm{C}-\mathrm{Cl}$} \\
\hline & $0.01 \mathrm{~m}$ & $0.001 \mathrm{~m}$ & $0.01 \mathrm{~m}$ & $0.001 \mathrm{~m}$ & $0.01 \mathrm{~m}$ & $0.001 \mathrm{~m}$ & $0.01 \mathrm{~m}$ & $0.001 \mathrm{~m}$ & $0.01 \mathrm{~m}$ & $0.001 \mathrm{~m}$ \\
\hline 0 & -- & -- & 2928.04 & 2929.97 & 1668.48 & 1668.48 & 1093.67 & 1093.14 & 657.75 & 657.75 \\
\hline 10 & 3456.55 & 3458.48 & 2929.97 & 2931.90 & 1668.48 & $1674.27,1662.69$ & 1093.67 & 1093.14 & 659.68 & 659.68 \\
\hline 20 & $\begin{array}{l}3439.1 \\
3429.55\end{array}$ & 3452.70 & 2931.90 & 2933.83 & $\begin{array}{l}1676.20 \\
1668.48\end{array}$ & 1668.48 & 1093.67 & 1093.14 & 661.61 & 659.68 \\
\hline 30 & 3421.83 & 3431.48 & 2933.83 & 2935.76 & 1668.48 & $1674.27,1662.69$ & 1095.60 & 1095.60 & 661.61 & 661.61 \\
\hline 40 & 3417.98 & 3421.83 & 2935.76 & 2937.68 & 1670.41 & 1666.55 & 1097.53 & 1097.53 & 661.61 & 661.61 \\
\hline 50 & 3414.12 & 3419.9 & 2937.68 & 2939.61 & 1670.41 & 1670.41 & 1097.53 & 1097.53 & 661.61 & 661.61 \\
\hline 60 & 3383.26 & 3379.4 & 2939.61 & 2939.61 & 1668.48 & 1670.41 & 1099.46 & 1099.46 & 663.54 & 663.54 \\
\hline 70 & 3365.9 & 3354.32 & 2941.54 & 2941.54 & 1668.48 & 1670.41 & 1099.46 & 1099.46 & 663.54 & 663.54 \\
\hline 80 & 3348.54 & 3348.54 & 2943.47 & 2943.47 & 1668.48 & 1670.41 & 1101.39 & 1101.39 & 663.54 & 663.54 \\
\hline 90 & 3344.68 & 3346.61 & 2943.47 & 2943.47 & 1668.48 & 1668.48 & 1103.32 & 1101.39 & 663.54 & 661.61 \\
\hline 100 & $\begin{array}{l}3350.46, \\
3333.10\end{array}$ & $\begin{array}{l}3348.54 \\
3336.96\end{array}$ & $\begin{array}{c}2945.40 \\
\text { (Alcohol) }\end{array}$ & $\begin{array}{c}2945.40 \\
\text { (Alcohol) }\end{array}$ & -- & -- & 1114.89 & 1114.89 & 657.75 & 719.47 \\
\hline
\end{tabular}

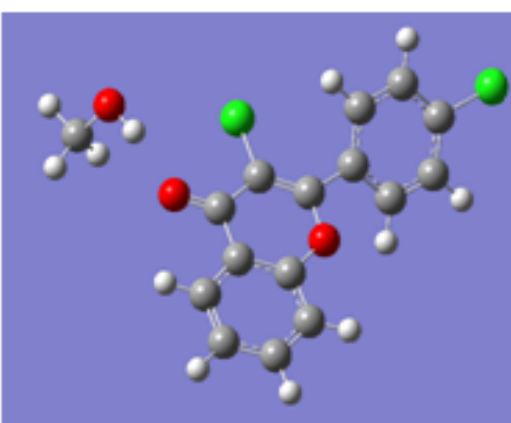

(a) $\mathrm{CL}_{1}+\mathrm{ME}$

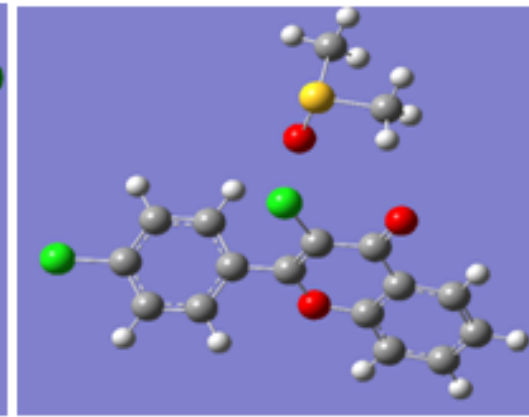

(b) $\mathrm{CL}_{1}+\mathrm{DMS}$

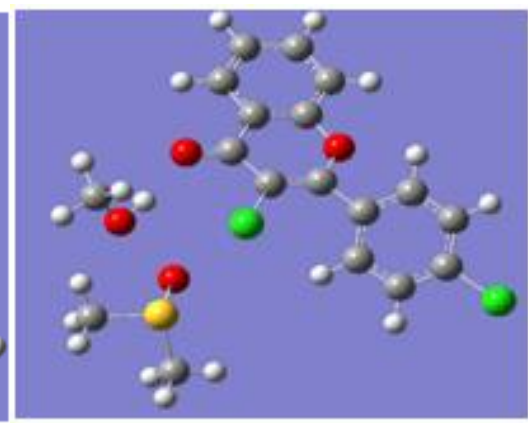

(c) $\mathrm{CL}_{1}+\mathrm{ME}+\mathrm{DMSO}$

Fig.7. Minimum energy complexes of $\mathrm{CL}_{1}$, ME and DMSO using DFT, B3LYP/6-31G(d) basis set

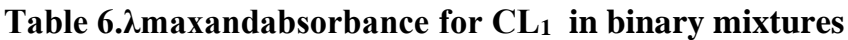

\begin{tabular}{|c|c|c|c|}
\hline & \% ME & $\boldsymbol{\lambda}_{\text {max }}$ & Absorbance \\
\hline \multirow{7}{*}{ ME + } & 0 & -- & -- \\
\cline { 2 - 4 } & 10 & 248 & 4 \\
\cline { 2 - 4 } & 20 & 247 & 4.00 \\
\cline { 2 - 4 } & 30 & 235 & 4 \\
\cline { 2 - 4 } & 40 & 300 & 0.68 \\
\cline { 2 - 4 } & 50 & 299 & 0.77 \\
\cline { 2 - 4 } & 60 & 300 & 1.12 \\
\cline { 2 - 4 } & 80 & 300 & 0.68 \\
\cline { 2 - 4 } & 90 & 300 & 0.94 \\
\hline \multirow{5}{*}{ ME + DMF } & 100 & 297 & 0.15 \\
\cline { 2 - 4 } & 0 & 255 & 0.59 \\
\cline { 2 - 4 } & 10 & 238 & 3.68 \\
\cline { 2 - 4 } & 20 & 238 & 3.76 \\
\cline { 2 - 4 } & 30 & 238 & 3.76 \\
\cline { 2 - 4 } & 40 & 299,297 & $1.88,0.77$ \\
\hline \multirow{7}{*}{ DMSO } & 297 & 0.95 \\
\hline
\end{tabular}


DOI: $10.17148 /$ IARJSET.2021.8617

\begin{tabular}{|c|c|c|c|}
\hline \multirow{7}{*}{} & 60 & 297 & 1.07 \\
\cline { 2 - 4 } & 80 & 297 & 1.25 \\
\cline { 2 - 4 } & 90 & 293 & 0.79 \\
\cline { 2 - 4 } & 100 & 297 & 0.15 \\
\hline
\end{tabular}

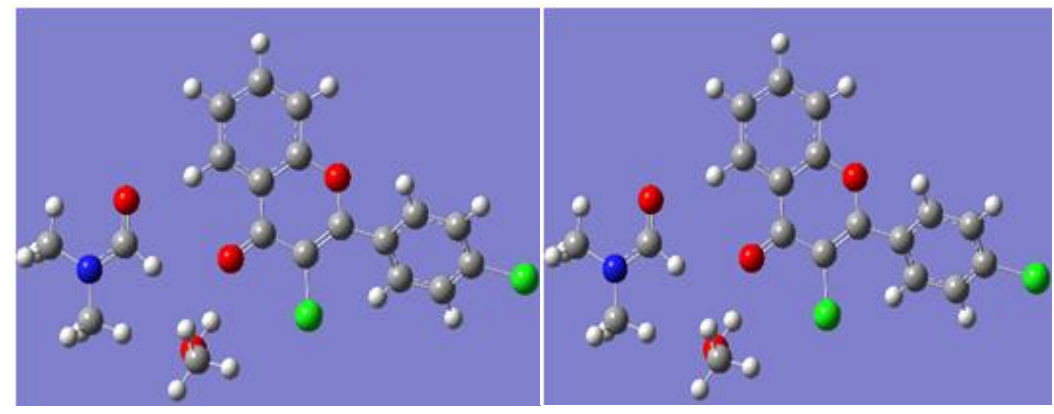

$\mathrm{CL}_{1}+\mathrm{DMF}$

$\mathrm{CL}_{1}+\mathrm{ME}+\mathrm{DMF}$

Fig.8. DFT optimized geometries of $\mathrm{CL}_{1}$, ME and DMF complexes using B3LYP/6-31G(d) basis set

The lowest energy structures of $\mathrm{CL}_{1}+\mathrm{ME}+\mathrm{DMSO}$ obtained by DFT study are highlighted in Fig. 7. We see that ME forms hydrogen bond with $\mathrm{C}=\mathrm{O}$ of $\mathrm{CL}_{1}$. The same oxygen of $\mathrm{ME}$ is close to sulphur atom of DMSO indicating dipoledipole interactions. In case of $\mathrm{CL}_{1}+\mathrm{ME}+\mathrm{DMF}$ (Fig. 8), a 3-centered hydrogen bond is seen between a aldehyde hydrogen and a hydroxy hydrogen of ME with oxygen of $\mathrm{C}=\mathrm{O}\left(\mathrm{CL}_{1}\right)$. Chlorine is free from interactions. For this system we find two $\mathrm{C}-\mathrm{H}$---O bonds. The first one is between aromatic ring hydrogen and DMF oxygen and the other is between methyl hydrogen of DMF oxygen of ME. This theoretical study supports all our conclusions drawn from the spectral studies for $\mathrm{CL}_{1}$ and $\mathrm{CL}_{2}$ in polar protic and aprotic solvent mixtures.

\section{CONCLUSION}

Hydrogen bonding plays an important role in both fundamental science and industrial applications. IR spectroscopy is one of the methods for identification of hydrogen bonds. UV spectroscopy deals with the excitation of non and pi bonding electrons. An irregular trends in $v \mathrm{OH}, v \mathrm{C}=\mathrm{O}, v \mathrm{~S}=\mathrm{O}, v \mathrm{C}-\mathrm{Cl}, v \mathrm{C}-\mathrm{H}, v \mathrm{NH}$ etc .with increase of ME in solution at a particular concentration of solute indicated structure of the medium changed with ME content. The $\lambda_{\max }$ of solutes vary with the $\%$ of ME. The decrease in $\lambda_{\max }$ of all solutes was more in ME + DMSO than in ME + DMF. The amount of blue shift (lower wave length) has been used as a measure to the strength of hydrogen bond. Absence of $n \rightarrow \pi^{*}$ excitation in solute + ME + DMSO/ DMF was ascribed due to hydrogen bond formation. Theoretical quantum calculations of these systems using GO3 (W) software improved our knowledge of kinds of intermolecular interactions taking place in systems. In this dissertation, we are giving the optimized geometries only. For this purpose Gauss View 4.1 package was used.From the optimized geometries of $\mathrm{CL}_{1}$ in $\mathrm{ME}+\mathrm{DMSO} / \mathrm{DMF}$ we conclude that ME forms hydrogen bond with $\mathrm{N}-$ $\mathrm{H} / \mathrm{C}=\mathrm{O}$ of solute The oxygen of ME was very close to sulphur atom of DMSO showing dipole-dipole interactions between them. Very interesting result of this study was the formation of 3-centered hydrogen bond between two hydrogen atoms of aromatic rings of solute and sulphur atom of DMSO. Distinguish between $v \mathrm{OH}$ and $v \mathrm{NH}$ is generally difficult because these frequencies appear in the same region $\left(3500-3300 \mathrm{~cm}^{-1}\right)$. With Density Functional Theory at $6-$ $31 \mathrm{G}$ (d) basis set, the 1:1:1 complex showed presence of both intra and intermolecular hydrogen bonds for $\mathrm{CL}_{1}$. ME formed hydrogen bond with oxygen of DMSO. The same oxygen of ME formed hydrogen bond with $\mathrm{N}-\mathrm{H}$ of $\mathrm{CL}_{1}$. The formation of 3-centered hydrogen bond takes place amongst $\mathrm{N}-\mathrm{H}$ hydrogen of $\mathrm{CL}_{1}$ and DMSO methyl hydrogen with nitrogen of $\mathrm{C}=\mathrm{N}$ of aromatic ring $\left(\mathrm{CL}_{1}\right)$.

\section{ACKNOWLEDGEMENT}

The author is thankful to Hon. Members of the management committee, Pimpalner education society, Pimpalner and also to the Principal of the College for providing facilities. My sincere thank and appreciation to Arunkumar B. Sawant, Ex. Professor in Chemistry, M. S. G. College, Malegaon Camp (Nashik), for his valuable and masterly guidance.

\section{REFERENCES}

[1]. Jamode V S, Chandak H S \& Bhagat P R, Asian J Chem, 16 (2004) 233; Chem Abstr, 141 (2004) 243402s.

[2]. Koregaokar S S, Patil P H, Shah M T \& Parekh H H, Indian J Pharm Sci, 58 (1996) 222.

[3]. Babu V H, Manna S K, Sneha, Srinivasan K K\& Bhat G V, Indian J Hetercycl Chem, 13 (2004) 253; Chem Abstr, 141 (2004) 31422 7b. 


\section{IARJSET}

\section{International Advanced Research Journal in Science, Engineering and Technology}

Vol. 8, Issue 6, June 2021

DOI: $10.17148 /$ IARJSET.2021.8617

[4]. Taylor E C, Patel H \& Kumar H, Tetrahedron, 48 (1992) 8089.

[5]. Ruhoglu O, Ozdemir Z, Calis U, Gumusel B \&Bilgin A A, ArzneimForesch, 55, (2005) 431

[6]. Chauhan R K, Yoon S J, Lee H, Kang M C and Min B M ; J Chem Eng Data,48 (2003) 291.

[7]. Forkmann G and Heller W, "Comprehensive Natural Products Chemistry", Barton D, Nakanishiv K, Meth-Cohn 0 (Eds.) (Elservier Science, Amsterdam), (1999)713

[8]. Agrawal N N and Soni P A; Indian J Chem, 44B (2005) 2601. a) Geissman T A and Harborne J B ; J Am Chem Soc, 78 (956) 832. b) Harbrone J B

[9]. Rao Y J, Reddy C R, Gangadhar N and David Krupadanam G L ; Indian J Chem, 48B (2009)1329.

[10]. Mahadevan K M, Basavaraj K M, Prathima Mathias D A and Vaidya V P, Indian J Chem, 44B (2005) 789.

[11]. El-Sawy, Shaker K H, Mandour A H, El-Din A S and Abdula M M, Indian J Chem, 47 (2008) 1451.

[12]. Karabasanagouda T, Airody V A and Girisha M; Indian J Chem, 48B (2009) 430.

[13]. Hasan M, Kadam U B, Hiray A P and Sawant A B; J Chem Eng Data, 51 (2006) 1797.

[14]. Davis, B.J., Carney, P.S. \& Bhargava, R. Theory of mid-infrared absorption micro spectroscopy: II. Heterogeneous samples. Anal. Chem. 82, 3487-3499 (2010).

[15]. Frisch M J et al Gaussian 03, Revision E01 Gaussian, Inc., Wallingford CT, USA 2004. 